\title{
IDENTIFIKASI FAKTOR-FAKTOR KEPUTUSAN KONSUMEN DALAM MEMBELI KOPI ARABIKA MANGLAYANG KARLINA DI WARUNG KOPI KIWARI
}

\author{
Kuswarini Kusno $^{1}$, Muhammad Fadli ${ }^{2}$, Tuti Karyani ${ }^{1}$, Endah Djuwendah ${ }^{1}$ \\ ${ }^{1}$ Prodi Agribisnis Fakultas Pertanian Universitas Padjadjaran, \\ kuswarini.kusno@unpad.ac.id \\ ${ }^{2}$ Alumni Prodi Agibisnis Fakultas Pertanian Universitas Padjadjaran
}

\begin{abstract}
Abstrak
Kiwari Farmers adalah suatu kelompok tani yang memproduksi kopi arabika yang diberi nama Manglayang Karlina dan dipasarkan di Warung Kopi Kiwari yang terletak di Jalan Palapa No.55, Padasuka, Cimenyan, Bandung, Jawa Barat. Maraknya kedai kopi di daerah Bandung menyebabkan persaingan bisnis semakin ketat sehingga terjadi fluktuasi dalam omzet penjualan kopi di Warung Kopi Kiwari. Salah satu upaya untuk mempertahankan eksistensinya, warung Kopi Kiwari perlu mengetahui bagaimana perilaku konsumennya. Penelitian ini bertujuan untuk mengidentifikasi faktor-faktor yang mempengaruhi konsumen dalam keputusan pembelian kopi Manglayang Karlina di warung Kopi Kiwari. Desain penelitian ini adalah desain kuantitatif dengan teknik penelitian survey terhadap 50 responden. Pemilihan responden dilakukan dengan menggunakan teknik purposive sampling. Data dianalisis secara deskriptif dengan menggunakan tabel frekuensi. Dari 11 faktor diperoleh 10 faktor yang mempengaruhi konsumen dalam membeli kopi arabika Manglayang Karlina, yaitu faktor budaya, sosial, psikologis, produk, harga, tempat, promosi, orang, proses dan faktor bukti fisik. Disarankan Warung Kopi Kiwari memberikan informasi mengenai manfaat kopi dan suatu konten menarik melalui media sosial yang sudah dimilikinya. Konten menarik dapat berupa informasi pemanfaatan ampas kopi untuk pengharum ruangan.
\end{abstract}

Kata kunci: kedai kopi, keputusan pembelian, perilaku konsumen

\begin{abstract}
Kiwari Farmers is a farmer group that produces Arabica coffee named Manglayang Karlina and is marketed at the Kiwari Coffee shop located on Jalan Palapa No.55, Padasuka, Cimenyan, Bandung, West Java. The rise of coffee shops in the Bandung area has caused tighter business competition resulting in fluctuations in coffee sales turnover at the Kiwari Coffee shop. One of the efforts to maintain its existence, the Kiwari Coffee shop needs to know how consumers behave. This study aims to identify the factors that influence consumers in the decision to purchase Manglayang Karlina coffee in Kiwari Coffee shop. The design of this study is a qualitative design with survey research techniques of 50 respondents. The selection of respondents was carried out using a purposive sampling technique. Data were analyzed descriptively using a frequency table. Of the 11 factors, 10 factors that influence consumers in buying Arabica Manglayang Karlina coffee are obtained, namely social factors, psychological, product, price, place, promotion, people, processes and physical factors. It is recommended that Warung Kopi Kiwari provide information about the benefits of coffee and an interesting content through social media that it already has. Interesting content can be information on the use of coffee grounds for air freshener.
\end{abstract}

Keywords: coffee shop, purchasing decisions, consumer behavior 


\section{Pendahuluan}

Hasil produksi kopi Indonesia menempati peringkat ke empat di dunia setelah Brazil, Colombia, dan Vietnam (ICO, 2018); dan berdasarkan data pada Tabel 1, rata-rata $71 \%$ produksi kopi tersebut untuk diekspor (Kementrian Pertanian, 2018).

Tabel 1.

Produksi, volume, dan nilai ekspor kopi Indonesia

\begin{tabular}{l|c|c|c}
\hline \multirow{2}{*}{ Tahun } & \multirow{2}{*}{$\begin{array}{l}\text { Produksi } \\
\text { (ton) }\end{array}$} & \multicolumn{2}{|c}{ Ekspor } \\
\cline { 3 - 4 } & 675.881 & 534.023 & 1.174 .029 \\
\hline 2013 & 647.857 & 384.816 & 1.039 .341 \\
\hline 2014 & 61 (x1000USD) \\
\hline 2015 & 639.412 & 502.021 & 1.197 .735 \\
\hline 2016 & 639.305 & 414.651 & 1.008 .549 \\
\hline 2017 & 637.539 & 467.799 & 1.187 .157 \\
\hline
\end{tabular}

Sumber: Kementrian Pertanian, 2018.

Ada dua jenis kopi yang dibudidayakan di Indonesia yakni arabika dan robusta seluas kurang lebih 1,3 juta hektar yang terletak di Sumatera Utara, Jawa, dan Sulawesi (Martaulli, 2018). Menurut Rukmana (2014), kopi arabika terbaik di dunia diproduksi oleh Indonesia.

Salah satu provinsi di Pulau Jawa yang memproduksi kopi terbesar adalah Jawa Barat. Di Jawa Barat, daerah penghasil kopi tertinggi adalah Kabupaten Bandung dimana produksinya mencapai 5.401 ton; sedangkan total produksi kopi Jawa Barat sebesar 18.123 ton (BPS, 2018 dalam Karyani et. al., 2019). Pada tahun 2013, Kabupaten Bandung ini merupakan penghasil kopi arabika terbesar (Ditjen Perkebunan, 2014 dalam_Kusno et. al., 2019).

Sementara itu, konsumsi kopi di Indonesia pada tahun 2016 mencapai 4,6 juta kemasan $60 \mathrm{~kg}$ atau sama dengan 276.000 ton (ICO, 2018), seperti tampak dalam Gambar 1. Tingkat konsumsi kopi Indonesia tersebut berada pada urutan ke enam setelah negaranegara Uni Eropa, Amerika, Brazil, Jepang, dan Rusia (ICO, 2018). Dari Gambar 1 dapat dilihat pula bahwa selama periode tahun
2016-2017 kebutuhan masyarakat Indonesia akan kopi meningkat. Hal ini disebabkan antara lain semakin dikenalnya produkproduk kopi di pasar sendiri, bertumbuhnya kedai-kedai kopi (cafe), dan lain-lain. Yang jelas peningkatan konsumsi kopi tersebut menandakan minat masyarakat meningkat terhadap produk kopi. Perubahan gaya hidup dan pola perilaku masyarakat yang konsumtif juga menjadi salah satu pemicu dari meningkatnya konsumsi kopi di Indonesia (Solikatun, 2015).

Kopi biasanya diolah menjadi minuman yang memiliki cita rasa khas yang tidak dimiliki oleh bahan minuman lainnya. Selain itu kopi merupakan sumber alami

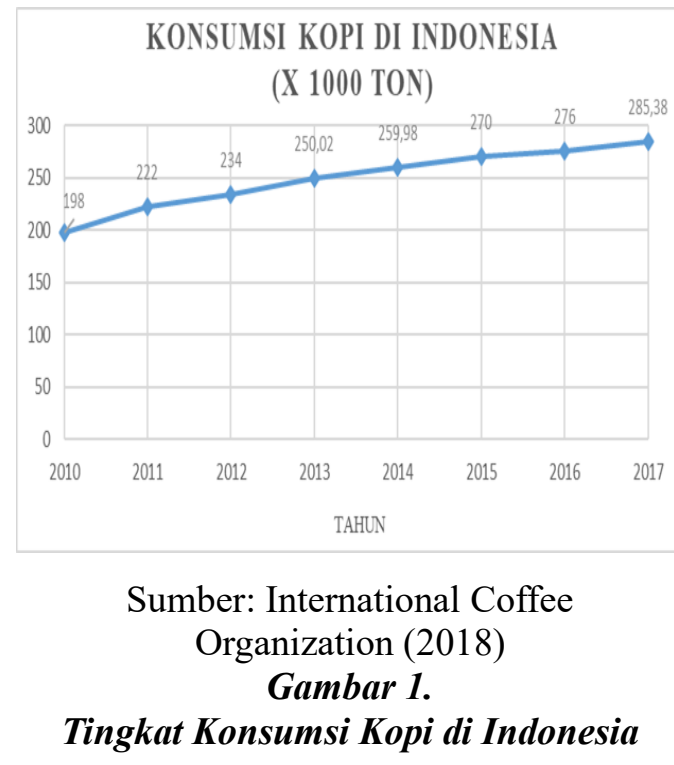

kafein (Nawrot et al, 2003), yaitu zat yang dapat menyebabkan peningkatan kewaspadaan dan mengurangi kelelahan (Smith, 2002). Hal inilah yang menjadi salah satu penyebab kopi mempunyai daya tarik tersendiri bagi konsumen kopi khususnya di Indonesia.

Kenaikan konsumsi kopi pada kota-kota besar di Indonesia diprediksi akan lebih tinggi, apalagi dengan adanya kebutuhan minum kopi bagi kalangan anak muda (BPTP Jawa Barat, 2017). Meningkatnya konsumsi kopi di Indonesia menunjukkan bahwa konsumsi kopi dalam negeri merupakan pasar yang potensial dan sekaligus menjadi peluang bisnis bagi para 
pelaku usaha di Indonesia. Investasi pada industri kopi yang menarik para pelaku usaha dan dinilai sebagai peluang bisnis yang baik adalah bisnis kafe dengan konsep kedai kopi.

Kedai kopi merupakan salah satu jenis restoran yang dipandang sebagai salah satu tempat yang dapat mewakili gaya hidup sebagian masyarakat. Selain untuk menikmati kopi, biasanya kedai kopi dimanfaatkan sebagai tempat berkumpul, bersantai, mengerjakan tugas, rapat, berdiskusi, dan lain lain. Suasana yang nyaman, rasa dan variasi menu serta fasilitas pendukung yang banyak ditawarkan merupakan beberapa alasan yang menjadikan kedai kopi sebagai pilihan tempat untuk berkumpul.

Silviatni dan Hariwan (2014) menyatakan bahwa Bandung sebagai salah satu simbol wisata kuliner, tidak ketinggalan dalam perkembangan bisnis kedai kopi. Selanjutnya Silviatni dan Hariwan (2014) mengungkapkan bahwa kini kedai kopi menawarkan fasilitas yang memberikan kenyamanan bagi konsumennya seperti akses internet, dan desain interior yang unik yang belum pernah ada sebelumnya, dan sebagainya. Pengamatan lapangan menunjukkan bahwa di daerah Bandung, kedai kopi sangat beragam, dari yang hanya khusus menyediakan kopi hingga kedai kopi yang menyediakan kopi serta makanan pelengkap lainnya. Menurut www.pergidulu.com (2017), terdapat 26 kedai kopi di Bandung.

Kiwari Farmers adalah suatu kelompok tani kopi sekaligus industri kreatif yang menjadi produsen kopi arabika di daerah Jawa Barat. Salah satu usahanya adalah kedai kopi yang bernama Warung kopi Kiwari. Fokus utama Warung kopi Kiwari adalah menjual kopi Manglayang Karlina dalam bentuk roast beans atau biji kopi yang sudah disangrai, ground beans atau biji kopi yang sudah digiling, dan dalam bentuk minuman kopi yang sudah diseduh. Kopi dalam bentuk roast beans dan ground beans dijual untuk konsumen yang ingin menyeduh kopi di tempat lain seperti di kantor atau di rumah. Meningkatnya jumlah kedai kopi di daerah Bandung menimbulkan persaingan yang semakin ketat dalam industri kopi. Hal tersebut dikarenakan konsumen kopi memiliki selera dan pilihan yang beragam. Salah satu dampak persaingan tersebut adalah omzet Warung Kiwari berfluktuasi selama bulan Januari hingga Juni 2018 (Gambar 2). Dari gambar tersebut dapat dilihat bahwa penurunan omzet terbesar terjadi pada Maret 2018. Hal ini dapat disebabkan oleh penurunan jumlah konsumen.

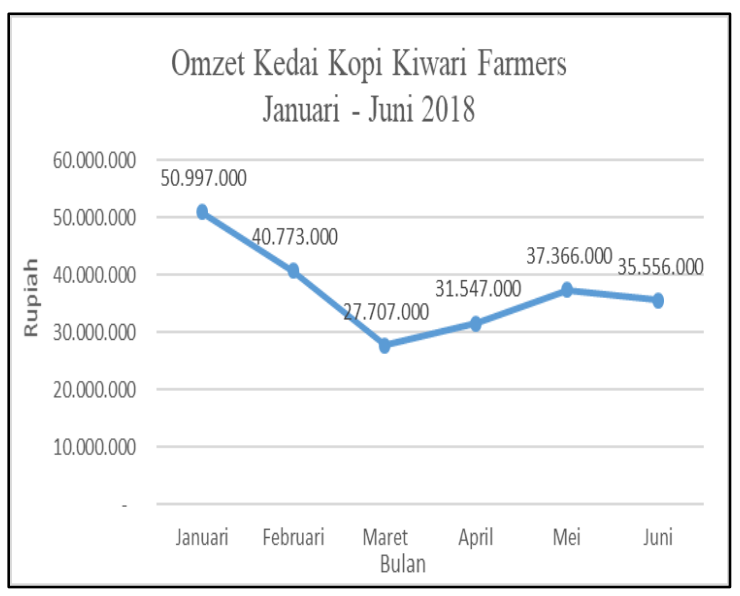

Sumber: Kiwari Farmers, 2018

Gambar 2.

Omzet Warung Kopi Kiwari

Warung Kopi Kiwari dituntut untuk tetap mempertahankan eksistensinya di tengah maraknya persaingan antar kedai kopi di daerah Bandung. Persaingan antar pelaku bisnis kopi dalam hal atribut yang relatif hampir sama seperti atmosfer tempat, menu yang ditawarkan, dan harga yang bersaing. Hal tersebut membuat para produsen harus memiliki sesuatu yang unik agar dapat menarik minat konsumen untuk datang ke kedai kopi mereka. Oleh karena itu, agar suatu kedai kopi dapat tetap bertahan dan menjaga eksistensinya dalam industri kopi, mereka harus mengetahui bagaimana perilaku konsumen dalam melakukan pembelian kopi (Charina, 2016).

Berdasarkan uraian yang dipaparkan di atas, penelitian ini bertujuan untuk 
mengidentifikasi faktor-faktor yang mempengaruhi konsumen dalam memutuskan membeli kopi arabika Manglayang Karlina di Warung Kopi Kiwari.

\section{Metode Penelitian}

Penelitian ini menggunakan desain kuantitatif dengan teknik survey terhadap 50 responden. Metode kuantitatif meliputi proses pengumpulan, analisis, interpretasi, dan penulisan hasil penelitian (Creswell, 2010). Sedangkan survey adalah pengumpulan data dan informasi secara sistematik dari responden dengan maksud untuk memahami aspek perilaku dari populasi yang diteliti (Sekaran, 2011), Penelitian dilakukan pada konsumen yang membeli kopi Manglayang Karlina di warung kopi Kiwari. Pemilihan responden dilakukan secara sengaja dengan kriteria bahwa responden telah membeli dan mengonsumsi kopi Manglayang Karlina 2 kali atau lebih dalam jangka waktu 3 bulan terakhir.

Perilaku pembelian konsumen dipengaruhi oleh faktor-faktor budaya, sosial, pribadi, dan psikologis (Kotler \& Keller 2009). Sedangkan dari sisi perusahaan, untuk mencapai tujuannya, perusahaan menggunakan seperangkat alat pemasaran yang disebut sebagai bauran pemasaran dimana terdiri dari: product, price, place, promotion, people, process, dan physical evidence,(Kotler \& Keller, 2009). Dengan demikian terdapat 11 faktor dalam penelitian ini. Data terdiri dari data primer dan sekunder. Data sekunder diperoleh dari hasil penelitian terdahulu, buku yang berkaitan dengan topik penelitian, dokumentasi pada saat melakukan pengumpulan data di warung kopi Kiwari, serta situs resmi instansi terkait seperti BPS, Dinas Perkebunan dan Kementrian Pertanian, dan lain-lain. Sedangkan data primer dikumpulkan dengan menggunakan kuesioner dan wawancara yang dilakukan pada hari biasa dan akhir pekan. Pengukuran data primer menggunakan skala ordinal 4 kelas yang digunakan untuk memperbolehkan seorang responden mengekspresikan seberapa besar ia setuju atau tidak setuju terhadap pernyataan tertentu. Dalam penelitian ini, sangat tidak setuju diberi nilai 1, tidak setuju 2, setuju 3, dan sangat setuju diberi nilai 4. Sebelum mengumpulkan data primer dengan kuesioner, kuesioner tersebut diuji terlebih dahulu validitas dan reliabiltasnya. Kedua uji tersebut dijelaskan sebagai berikut:

Uji Validitas berkenaan dengan pertanyaan sampai sejauh mana data yang dikumpulkan pada suatu kuesioner dapat mengukur apa yang akan diukur. Rumusnya adalah (Anderson, Sweeney \& Williams (2002):

$r_{\mathrm{xy}}=\frac{\mathrm{N} \sum \mathrm{XY}-\left(\sum \mathrm{X}\right)\left(\sum \mathrm{Y}\right)}{\sqrt{\left(\mathrm{N} \sum \mathrm{X}^{2}-\left(\sum \mathrm{X}\right)^{2}\right)\left(\mathrm{N} \sum \mathrm{Y}^{2}-\left(\sum \mathrm{Y}\right)^{2}\right)}}$

$\mathrm{r}_{\mathrm{xy}}=$ Koefisien korelasi

$\sum \mathrm{X}=$ Jumlah skor item pernyataan

$\sum \mathrm{Y}=$ jumlah skor total

$\mathrm{N}=$ banyaknya responden

$\sum X^{2}=$ jumlah kuadrat skor item

$\sum \mathrm{Y}^{2}=$ jumlah kuadrat skor total

$\sum X Y=$ total perkalian skor item

Apabila $r_{x y}$ lebih besar dari $r$ table maka kuesioner dikatakan valid.

Uji reliabiltas bertujuan mengukur konsistensi. Kuesioner dikatakan reliabel jika dapat memberikan hasil relatif sama pada saat dilakukan pengukuran kembali pada obyek yang berlainan pada waktu yang berbeda atau memberikan hasil yang tetap. Rumus yang digunakan adalah Cronbach Alpha sebagai berikut:

$\mathrm{r}_{11}=\left(\frac{\mathrm{k}}{\mathrm{k}-1}\right)\left(1-\frac{\sum \sigma_{\mathrm{b}}^{2}}{\sigma_{\mathrm{t}}^{2}}\right)$

$\mathrm{r}_{11}=$ realibilitas kuesioner

$\sum \sigma_{\mathrm{b}}^{2}=$ jumlah varians item

$\mathrm{K}$ = banyaknya item pernyataan

$\sigma_{\mathrm{t}}^{2} \quad=$ varians total

Kuesioner dinyatakan reliabel jika $r_{11}$ lebih besar dari $r$ table.

Kedua uji tersebut diterapkan dengan menggunakan data responden yang berbeda 
dari kelima puluh responden penelitian (= N) untuk semua item pernyataan. Dalam penelitian ini banyaknya responden untuk uji validitas dan reliabilitas ditentukan $10 \%$, jadi sama dengan 5 orang. Pengujian ini dilakukan dengan bantuan program SPSS. Hasilnya menunjukkan kusioner valid dan reliabel.

Data kelima puluh responden kemudian dianalisis secara deskriptif dengan menggunakan tabel frekuensi. Untuk mengetahui faktor apa saja yang mempengaruhi konsumen dalam memutuskan membeli kopi arabika Manglayang Karlina, dilakukan prosedur membangun distribusi frekuensi sebagai berikut:

1. Mencari skor tertinggi yaitu $4 \times \mathrm{N}=4 \mathrm{x}$ $50=200$ dan skor terendah yaitu $1 \times \mathrm{N}=$ $1 \times 50=50$.

2. Menghitung interval kelas $\mathrm{p}$ :

$$
\begin{gathered}
\mathrm{p}=\frac{\text { skor tertinggi-skor terendah }}{\text { banyaknya kelas }}= \\
\frac{200-50}{4}=37,5 \rightarrow 37
\end{gathered}
$$

3. Menentukan batas bawah dan batas atas setiap kelas/kategori:

- 50-87 : sangat tidak setuju

- $88-125$ : tidak setuju

- $126-163$ : setuju

- 164 - 201: sangat setuju

Faktor apa saja yang menentukan keputusan konsumen adalah faktor-faktor yang memiliki rata-rata skor berkategori setuju dan sangat setuju.

\section{Hasil dan Pembahasan}

1) Faktor budaya, sosial, pribadi, dan faktor psikologis

Pada Tabel 2 tampak bahwa faktor budaya diukur oleh item pernyataan a yaitu kebiasaan dan frekuensi mengonsumsi kopi sehari-hari menjadi pertimbangan dalam membeli kopi. Kebiasaan merupakan

\section{Tabel 2}

\section{Tanggapan responden terhadap berbagai}

faktor yang dipertimbangkan dalam

\begin{tabular}{|c|c|c|c|c|c|c|}
\hline \multirow[b]{2}{*}{ Item } & \multicolumn{4}{|c|}{ Frekuensi } & \multirow{2}{*}{$\begin{array}{l}\text { Total } \\
\text { skor }\end{array}$} & \multirow{2}{*}{$\begin{array}{l}\text { Kate } \\
\text { gori }\end{array}$} \\
\hline & 1 & 2 & 3 & 4 & & \\
\hline \multicolumn{7}{|c|}{ Faktor budaya } \\
\hline $\mathrm{a}$ & 0 & 5 & 37 & 8 & 153 & $\mathrm{~S}$ \\
\hline \multicolumn{5}{|c|}{ Rata-rata skor } & 153 & $\mathbf{S}$ \\
\hline
\end{tabular}
keputusan pembelian kopi

\section{Faktor sosial}

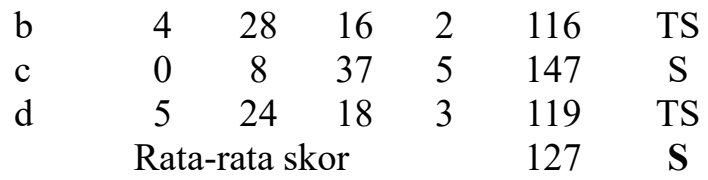

\section{Faktor pribadi}

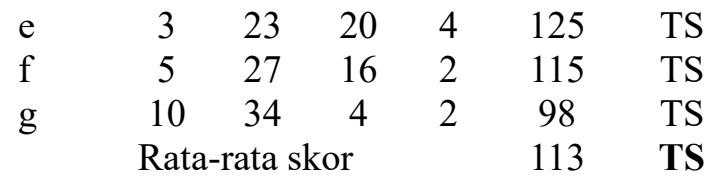

\section{Faktor psikologis}

\begin{tabular}{ccccccc}
$\mathrm{h}$ & 0 & 1 & 35 & 14 & 163 & $\mathrm{~S}$ \\
$\mathrm{i}$ & 1 & 14 & 31 & 4 & 138 & $\mathrm{~S}$ \\
$\mathrm{j}$ & 1 & 2 & 37 & 10 & 156 & $\mathrm{~S}$ \\
\multicolumn{5}{c}{ Rata-rata skor } \\
\hline
\end{tabular}

Keterangan: $\mathbf{1}=$ Sangat tidak setuju, $\mathbf{2}=$ tidak setuju, $\mathbf{3}=$ setuju, $\mathbf{4}=$ sangat setuju

cara bertindak yang diperoleh melalui belajar secara berulang-ulang, yang pada akhirnya menjadi menetap dan bersifat otomatis (Djaali, 2011). Mayoritas responden $(=37 / 50)$ setuju terhadap pernyataan a tersebut di atas karena kebiasaan berkaitan erat dengan frekuensi konsumsi kopi seseorang, biasanya dalam satuan gelas. Dilihat dari rata-rata skor yang $=153$, maka faktor budaya termasuk kategori setuju, artinya faktor budaya ini menentukan keputusan responden dalam membeli kopi. Hal tersebut disebabkan responden sudah terbiasa untuk mengonsumsi kopi dan menjadikan kegiatan tersebut sebagai kegiatan rutin.

Faktor sosial dicerminkan oleh item pernyataan $b$ : keluarga menjadi referensi dalam membeli kopi, c: rekan kerja menjadi referensi dalam membeli kopi, dan $\mathrm{d}$ : membeli kopi karena meningkatkan status sosial saat mengonsumsinya. Dari Tabel 2 dapat dilihat bahwa rata-rata skor kertiga item ini mencapai 127 dimana termasuk kategori setuju. Dengan demikian artinya 
faktor sosial mempengaruhi keputusan responden dalam membeli kopi Manglayang Karlina. Rekan kerja (item c) lebih dipertimbangkan responden sebagai referensi dalam membeli kopi daripada keluarga (item b). Hal tersebut ditunjukkan oleh kategori TS (Tidak Setuju) bagi item b dan S (Setuju) bagi item c. Hasil ini tidak sejalan dengan teori yang dijelaskan oleh Engel et al. (1994) yang menyatakan bahwa keluarga adalah pengaruh utama pada sikap dan perilaku individu dalam pengambilan keputusan pembelian. Selain itu, responden tidak setuju jika pertimbangan membeli kopi karena meningkatkan status sosial (item d). Hal tersebut tidak sesuai dengan teori yang dijelaskan oleh Solikatun (2015) yang menyatakan bahwa peminum kopi modern terbuka adalah peminum kopi yang memaknai perilaku mengonsumsi kopi untuk menunjukkan gaya hidup masyarakat modern, status sosial yang high class, prestis, mahal dan berkualitas.

Faktor pribadi diukur oleh item pernyataan e: usia menjadi pertimbangan dalam mengonsumsi kopi, f: jenis pekerjaan menjadi pertimbangan dalam mengonsumsi kopi, dan g: tingkat pendidikan menjadi pertimbangan dalam mengonsumsi kopi. Total skor masing-masing item tersebut pada Tabel 2 adalah 125, 115, dan 98. Ketiga skor tersebut terletak dalam selang $88-125$ artinya ketiga item faktor pribadi termasuk kelas/kategori tidak setuju (lihat butir 3 pada prosedur membangun distribusi frekuensi dalam bagian Metode Penelitian). Kesimpulannya, faktor pribadi tidak mempengaruhi keputusan responden dalam membeli kopi, sehingga dapat dikatakan bahwa mengonsumsi kopi sudah menjadi kebutuhan bagi responden tersebut.

Faktor psikologi diukur dengan 3 item pernyataan yakni h: membeli kopi karena menimbulkan perasaan nyaman saat mengonsumsinya, i: membeli kopi karena mengonsumsi kopi baik bagi kesehatan, serta j: membeli kopi karena dorongan dari dalam diri untuk mengonsumsinya.
Responden menyatakan setuju bahwa faktor psikologis mempengaruhi mereka dalam membeli kopi Manglayang Karlina; ini ditunjukkan oleh rata-rata skor $=152$ pada Tabel 2. Tujuan mereka mengonsumsi kopi adalah untuk menghilangkan rasa gundah atau perasaan tidak nyaman yang sedang mereka rasakan. Mereka berpendapat bahwa dengan mengonsumsi kopi dapat menimbulkan perasaan nyaman pada diri mereka. Hasil tersebut sesuai dengan teori yang dinyatakan oleh Solikatun (2015) bahwa peminum kopi memaknai minum kopi adalah suatu hal untuk mendapatkan ketenangan diri yang dapat merubah suasana hati atau mood. Selain itu, responden juga mempertibangkan manfaat yang baik bagi kesehatan saat mengonsumsi kopi. Hal itu merupakan motivasi mereka untuk mencari kepuasan saat mengonsumsi kopi.

\section{2) Faktor Bauran Pemasaran $7 P$}

Tanggapan responden terhadap ketujuh faktor bauran pemasaran disajikan dalam Tabel 3. Tampak bahwa rata-rata skor ketujuh faktor ini tidak ada yang menghasilkan kategori tidak setuju.

Tabel 3

Tanggapan responden terhadap faktor bauran pemasaran $7 P$

\begin{tabular}{ccccccc}
\hline \multirow{2}{*}{ Item } & \multicolumn{4}{c}{ Frekuensi } & Total & Kate \\
\cline { 2 - 4 } & $\mathbf{1}$ & $\mathbf{2}$ & $\mathbf{3}$ & $\mathbf{4}$ & skor & gori \\
\hline
\end{tabular}

\begin{tabular}{lcccccc}
\hline \multicolumn{7}{l}{ Faktor produk (product) } \\
$\mathrm{k}$ & 0 & 1 & 28 & 21 & 170 & $\mathrm{SS}$ \\
$\mathrm{l}$ & 0 & 2 & 29 & 19 & 167 & $\mathrm{SS}$ \\
$\mathrm{m}$ & 0 & 2 & 34 & 14 & 162 & $\mathrm{~S}$ \\
$\mathrm{n}$ & 0 & 6 & 33 & 11 & 155 & $\mathrm{~S}$ \\
\multicolumn{7}{c}{ Rata-rata skor } \\
\end{tabular}

Faktor harga (price)

\begin{tabular}{lcccccc} 
o & 0 & 9 & 32 & 9 & 150 & $\mathrm{~S}$ \\
$\mathrm{p}$ & 1 & 9 & 35 & 5 & 144 & $\mathrm{~S}$ \\
$\mathrm{q}$ & 0 & 0 & 31 & 19 & 169 & $\mathrm{SS}$ \\
\multicolumn{5}{l}{ Faktor tempat (place) } \\
$\mathrm{r}$ & 1 & 7 & 34 & 8 & 149 & $\mathrm{~S}$ \\
$\mathrm{~s}$ & 0 & 0 & 28 & 22 & 172 & $\mathrm{SS}$ \\
$\mathrm{t}$ & 0 & 2 & 32 & 16 & 164 & $\mathrm{SS}$ \\
& \multicolumn{7}{l}{ Rata-rata skor } & & 162 & $\mathrm{~S}$
\end{tabular}

Faktor promosi (promotion) 


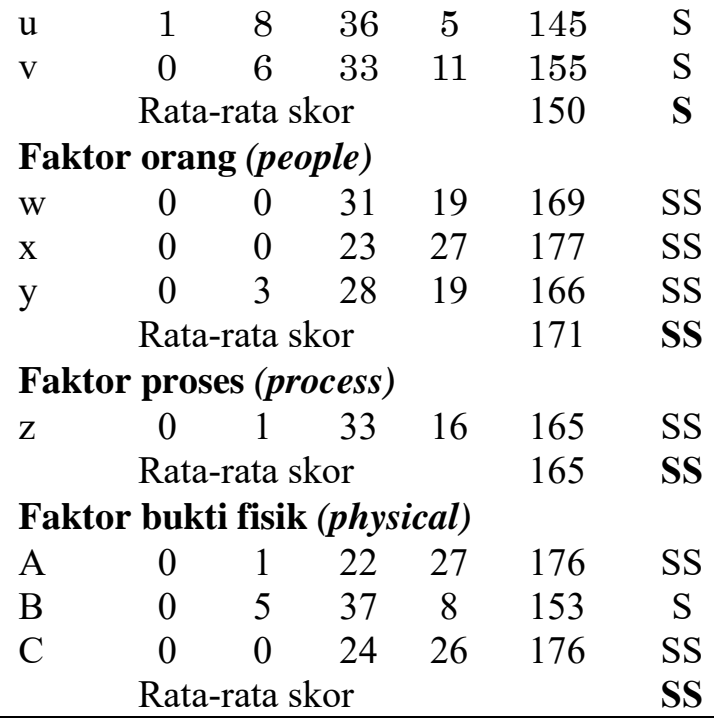

Keterangan: $\mathbf{1}=$ Sangat tidak setuju, $\mathbf{2}=$ tidak setuju, $\mathbf{3}=$ setuju, $\mathbf{4}=$ sangat setuju

Faktor produk terdiri dari pernyataan k: membeli kopi karena cita rasa yang sesuai, 1: membeli kopi karena aroma yang khas, m: membeli kopi karena menu kopi yang ditawarkan bervariasi, dan n: membeli kopi karena tampilan penyajiannya yang menarik. Berdasarkan Tabel 3, responden menyatakan sangat setuju bahwa faktor produk mempengaruhi mereka dalam membeli kopi Manglayang Karlina. Cita rasa yang sesuai dan aroma yang khas menjadi daya tarik tersendiri bagi responden tersebut. Kopi Manglayang Karlina memliki rasa yang cukup kompleks. Saat masih panas rasa kopi tersebut seperti buah lemon, buah belimbing dan sedikit rasa buah nanas. Kemudian saat sudah hangat rasa kopi berubah menjadi seperti kulit jeruk, dan karamel. Kopi tersebut juga memiliki aroma yang khas seperti kayu manis dan gula aren. Selain itu, responden juga tertarik dengan varian kopi Manglayang Karlina yang ditawarkan, seperti dicampur dengan susu, cafe latte, dan cappuccino. Kemudian, terdapat juga varian yang dibuat dengan proses berbeda seperti dibuat dengan air bersuhu ruangan yang diberi namacold brew. Kopi tersebut juga mempunyai tampilan yang menarik, seperti gelas yang berbentuk unik, kemasan roast beans yang dilengkapi dengan informasi tentang kopi tersebut dan cold brew yang disajikan dalam botol berbahan kaca.

Faktor harga diukur oleh item o: harga merupakan pertimbangan utama dalam membeli kopi, p: Pertimbangan pembelian kopi karena kesesuaian harga dengan kuantitas, dan q: Pertimbangan pembelian kopi karena kesesuaian harga dengan kualitas. Berdasarkan Tabel 3, responden menyatakan setuju bahwa faktor harga mempengaruhi mereka dalam membeli kopi. Harga, kuantitas dan kualitas merupakan suatu hal yang saling berkaitan satu sama lain. Kopi Manglayang Karlina memiliki harga yang terjangkau dan sesuai dengan kuantitas serta kualitas produk. Warung Kopi Kiwari selalu memperhatikan kualitas kopi mereka, salah satu caranya adalah dengan melakukan cupping coffee yang bertujuan untuk mengevaluasi kualitas kopi sebelum ditawarkan kepada responden.

Faktor tempat diukur oleh item r: pertimbangan pembelian kopi karena lokasi yang mudah dijangkau, s: pertimbangan pembelian kopi karena lokasi memberikan suasana yang nyaman saat mengonsumsi kopi, dan t: pertimbangan pembelian kopi karena lokasi memberikan suasana yang aman saat mengonsumsi kopi. Pada Tabel 3 dapat dilihat bahwa responden menyatakan setuju akan faktor tempat mempengaruhi mereka dalam membeli kopi Manglayang Karlina. Suasana yang aman dan nyaman membantu responden dalam mencapai tujuan mereka saat mengonsumsi kopi seperti bersantai, berdiskusi, mengerjakan tugas dan hal lainnya. Selain itu Warung Kopi Kiwari juga mempuyai tempat yang unik dan menarik karena lokasinya berada di dataran yang cukup tinggi, sehingga responden dapat menikmati suhu udara yang sejuk dan pemandangan kota Bandung yang indah.

Faktor promosi terdiri dari 2 item yaitu u: pemberian hadiah dapat menarik minat beli konsumen kopi, dan v: iklan sosial media yang menarik menjadi pertimbangan untuk membeli dan mengonsumsi kopi. 
Responden setuju bahwa faktor promosi mempengaruhi mereka dalam membeli kopi Manglayang Karlina. Pemberian hadiah dan iklan di sosial media merupakan salah satu promosi yang dilakukan Warung Kopi Kiwari. Hadiah yang diberikan berupa voucher discount 30\% produk kopi Manglayang Karlina. Hadiah lainnya adalah gratis kunjungan ke kebun kopi Kiwari Farmers apabila seseorang berhasil menjawab pertanyaan tertentu yang diberikan melalui media sosial Instagram. Warung Kopi Kiwari mempunyai media sosial yaitu Instagram (@kopi.kiwari), Facebook, Official Account Line, dan Whatsapp. Melalui media sosial tersebut biasanya Kiwari melakukan promosi kopi Manglayang Karlina berupa iklan dan informasi lain terkait kopi tersebut.

Faktor orang dicerminkan oleh item w: kesigapan pelayan dalam melayani konsumen menjadi pertimbangan untuk membeli kopi, x: keramahan dan kesopanan pelayan dalam melayani konsumen menjadi pertimbangan untuk membeli kopi , dan y: penampilan pelayan yang rapih dan bersih saat membuat atau menyajikan seduhan kopi menjadi pertimbangan untuk membeli kopi. responden menyatakan setuju bahwa faktor orang mempengaruhi mereka dalam membeli kopi Manglayang Karlina. Pelayan di warung Kopi Kiwari disebut sebagai barista. Menurut KBBI barista adalah orang yang ahli membuat minuman kopi (seperti espresso) di kafe atau di kedai kopi. Warung Kopi Kiwari mempunyai barista yang handal dan mampu bekerja sesuai dengan bidangnya dalam menyajikan kopi. Barista tersebut juga ramah terhadap responden. Menurut Rambat (2001), karyawan yang ramah sangat diperlukan dalam melayani konsumen, karena karyawan dapat secara langsung mempengaruhi keputusan konsumen untuk kembali. Penampilan barista Warung Kopi Kiwari juga rapih dan bersih saat membuat dan menyajikan kopi. Hal tersebut sudah menjadi prosedur operasional standar untuk seluruh barista warung Kopi Kiwari.
Faktor proses dikur oleh item $\mathrm{z}$ yaitu kecepatan proses pelayanan, penyajian dan transaksi menjadi pertimbangan untuk membeli kopi. Responden setuju bahwa faktor proses mempengaruhi mereka dalam membeli kopi Manglayang Karlina. Kecepatan proses pelayanan, penyajian dan transaksi sudah menjadi ciri khas di warung Kopi Kiwari. Hal itu dikarenakan barista tersebut sudah berpengalaman lama tentang apa yang mereka kerjakan. Barista yang masih baru akan mendapatkan pelatihan terlebih dahulu sebelum ditugaskan langsung di bar. Proses transaksi dilakukan dengan menggunakan sistem pencatatan digital dalam memproses pesanan responden. Mereka juga menerapkan sistem first in first out yang artinya pesanan yang pertama dipesan adalah pesanan yang harus disajikan terlebih dahuluFaktor bukti fisik diukur oleh item A: ketersediaan fasilitas seperti wi-fi, toilet, mushola dan tempat parkir menjadi pertimbangan untuk membeli kopi, B: pertimbangan pembelian dan konsumsi kopi karena konsep edukasi yang ditawarkan menarik, serta $\mathrm{C}$ : kebersihan serta kerapihan sarana dan prasarana yang tersedia menjadi pertimbangan untuk membeli kopi. Responden sangat setuju bahwa faktor bukti fisik mempengaruhi mereka dalam membeli kopi Manglayang Karlina. Fasilitas yang disediakan seperti $w i-f i$, toilet, mushola dan tempat parkir sangat membantu responden dalam melakukan kegiatan mereka seperti mengerjakan tugas, melakukan ibadah dan hal lainnya. Warung Kopi Kiwari juga menerapkan konsep edukasi yang menarik seperti public cupping, yaitu suatu kegiatan yang dilakukan bersama responden untuk mengevaluasi kopi yang akan dipasarkan. Selanjutnya barista akan meminta pendapat dari responden yang ikut berpartisipasi dan barista akan memberikan kesimpulan serta edukasi terkait hasil evaluasi tersebut. Kebersihan dan kerapihan sarana prasarana juga merupakan hal yang selalu dijaga oleh warung Kopi Kiwari. Salah satu cara yang dilakukan adalah dengan membersihkan sarana prasarana tersebut sebelum dan 
sesudah warung beroperasi. Seluruh barista mempunyai tanggung jawab untuk menjaga kebersihan dan kerapihan sarana prasarana tersebut. Tujuannya adalah agar responden lebih nyaman dalam mengonsumsi kopi.

\section{Kesimpulan}

Dari 11 faktor diperoleh 10 faktor yang mempengaruhi responden dalam membeli kopi arabika Manglayang Karlina di Warung Kopi Kiwari. Faktor-faktor tersebut adalah adalah faktor budaya, sosial, psikologis, produk, harga, tempat, promosi, orang, proses dan faktor bukti fisik.

Karena manfaat mengonsumsi kopi baik bagi kesehatan dan konten yang menarik pada media sosial menjadi pertimbangan konsumen dalam melakukan pembelian, maka disarankan Warung Kopi Kiwari memberikan informasi mengenai manfaat kopi tersebut dan suatu konten menarik melalui media sosial yang sudah dimiliki. Konten menarik yang dapat disampaikan misalnya informasi tentang pemanfaatan ampas kopi untuk didaur ulang menjadi pengharum ruangan.

\section{Daftar Pustaka}

Anderson, D.R., D.J. Sweeney and T.A. Williams. 2002. Statistics for Business and Economics 8th ed. Thomson Learning. South-Westren

Badan Pusat Statistik Indonesia. www.bps.go.id. Diakses pada Juli 2018.

BPTP Jawa Barat, 2017. Konsumsi Kopi Naik Drastis. disbun.jabarprov.go.id Diakses pada Desember 2019.

Charina, Deassy. 2016. Faktor-faktor yang Mempengaruhi Keputusan Pembelian Minuman Kopi di Malabar Mountain Café Kota Bogor. Skripsi. Departemen Agribisnis Fakultas Ekonomi dan Manajemen IPB

Creswell J W. 2010. Research Design.
Pendekatan Kualitatif, Kuantitatif dan Mixed. Edisi Ketiga (Terjemahan). Pustaka Pelajar: Yogyakarta

Direktorat Jenderal Perkebunan. 2014. Statistik Perkebunan Indonesia: Kopi 2013-2015. Kementerian Pertanian. Jakarta

Djaali. 2011. Psikologi Pendidikan. Bumi Aksara. Jakarta

Engel, James F, et.al, 1994, Consumer Behavior, Jilid 1, Alih Bahasa Budiyanto, Jakarta: Binarupa Aksara

International Coffee Organization (ICO). 2018. www.ico.org. Diakses pada Juli 2018

Karyani, Tuti. Mahaputra, Karl Andhika, Djuwendah, Endah. Kusno, Kuswarini. 2019. Dampak Pola Tanam Kopi Terhadap Pendapatan Petani (Suatu Kasus Di Desa Pulosari Kecamatan Pangalengan, Bandung). Jurnal Pemikiran Masyarakat Ilmiah Berwawasan Agribisnis. Januari 2020. 6(1): 101-112

Kotler, Philip \& Kevin L., Keller. (2009). Manajemen Pemasaran. Terjemahan: Bob Sabran. Edisi 13 Jilid 1 dan 2. Indonesia: Penerbit Erlangga

Kusno, Kuswarini. Arifin, M Indra Pratama. Wiyono, Sulystiodewi Nur. Rochdiani, Dini. 2019. Strategi Pemasaran Kopi Luwak Manglayang Karlina Di Kelompok Tani Kiwari Farmers, Kabupaten Bandung. Agricore Volume 4 Nomor 1, Juli 2019, hal. 632-641

Martaulli, Elvin Desi. 2018. Analisis Produksi Kopi Di Indonesia. Journal of Agribusiness Science. April 2018 Volume 01 No 02. hal. 112-120

Nawrot, P., S. Jordan., J. Eastwood., J. 
Rotstein., A. Hugenholtz., M. Feeley. 2003. Effects of Caffeine on Human Health. Food Additives and Contaminants. Vol. 20, No. 1, pp 1-30.

Rukmana, Rahmat. 2014. Untung Selangit dari Agribisnis Kopi. Yogyakarta: Lily Publisher.

Sekaran, Umar. 2000. Metode Penelitian Untuk Bisnis. Edisi Keempat. Penerjemah: Kwan Men Yon. Jakarta: Penerbit Salemba Empat.

Silviatni, Inggi dan Hariwan, Peggy. 2014. Perancangan Model Bisnis Café Zapateria. eProceedings of Management Vol. 1 No. 3 (2014) hal. 831 - 852

Smith, A. 2002. "Effects of Caffeine on Human Behavior. Food and Chemical Toxicology". Vol. 40, halaman 12431255.

Solikatun. Kartono, Drajat Tri. Demartoto, Argyo. 2015. Perilaku Konsumen Kopi sebagai Budaya Masyarakat Konsumsi: Studi Fenomenologi pada Peminum Kopi di Kedai Kopi Kota Semarang. Jurnal Analisa Sosiologi. April 2015, 4(1): 60 74 